\title{
Why Collaborate with Close Others When Choosing a College Major?
}

\author{
Ines Schindler ${ }^{1}$, Julia Dietrich ${ }^{2,3}$ \& Cynthia A. Berg ${ }^{1}$ \\ ${ }^{1}$ Department of Psychology, University of Utah, Salt Lake City, USA \\ ${ }^{2}$ Department of Psychology, University of Erfurt, Germany \\ ${ }^{3}$ Helsinki Collegium for Advanced Studies, University of Helsinki, Finland \\ Correspondence: Ines Schindler, Free University Berlin, Cluster "Languages of Emotion," Habelschwerdter \\ Allee 45, 14195 Berlin, Germany. Tel: 49-30-838-54379. E-mail: ines.schindler@fu-berlin.de
}

Received: December 13, 2013

Accepted: January 6, $2014 \quad$ Online Published: March 12, 2014

doi:10.5539/jedp.v4n1p128

URL: http://dx.doi.org/10.5539/jedp.v4n1p128

\begin{abstract}
In spite of increasing research interest in relational aspects of making important life decisions, our knowledge on why, how, and to what effect close others are involved in decision making still is limited. We determined whom our 65 participants (students between 18 and 27 years; 54\% women), in general, would like to collaborate with when making life choices that will shape their future identities. We further investigated under which conditions consulting with this generally preferred advisor (PA) was related to satisfaction with a specific real-life choice, namely, choosing a college major. This one-year prospective longitudinal study included repeated assessments as students chose a major, including monthly reports on the persons that had been involved in choosing a major. These were followed by qualitative and quantitative assessments of evaluations of one's PA as collaborator. Our findings revealed that involvement of one's PA during major choice was related to greater indecision regarding one's choice, but not to the PA's perceived quality. Involvement of the PA further was related to greater choice satisfaction only when the PA was perceived as highly familiar with the student, experienced in collaborating with him or her, and helpful in optimizing decisions. Our findings suggest that close others can be an important resource for making satisfactory life choices that could also be drawn upon in professional counseling contexts.
\end{abstract}

Keywords: preferred advisor, college major choice, collaboration, social involvement, choice satisfaction, indecision

\section{Introduction}

During the last few decades, theorizing and research on career-related decisions and transitions (e.g., Blustein, 2011; Dietrich, Parker, \& Salmela-Aro, 2012; Flum, 2001; Phillips, Christopher-Sisk, \& Gravino, 2001; Schultheiss, Kress, Manzi, \& Glasscock, 2001; Young et al., 2008) as well as on decision making and problem solving more generally (e.g., Berg \& Upchurch, 2007; Bonaccio \& Dalal, 2006) has increasingly highlighted the situated nature of decisions, problems, and transitions within relational contexts. The different ways of how individuals connect to others influence how these individuals engage in exploring themselves and their options and how they make choices. Considering this web of relationships surrounding life choices also is of importance to understanding identity development.

In this paper, we sought to further our understanding of the role of close relationship partners for making satisfying career decisions by investigating how students actively draw on a relational resource to inform their choice of college major. Specifically, we asked students to nominate and evaluate a preferred advisor (PA), that is, the person whose assistance they would preferably seek when making important life choices. Extant studies of relational influences on career choice and development (e.g., Dietrich, Kracke, \& Nurmi, 2011; Germeijs \& Verschueren, 2009; Kracke, 2002; Marshall, Young, Domene, \& Zaidman-Zait, 2008) often have focused on certain types of relationship partners presumed to be most important (e.g., parents). While this research has produced important insights, it is limited to the studied relationship partners and, thus, may have overlooked other partners for decision making.

The present study further adds to the literature by offering a prospective investigation of when involvement of one's PA in major choice is related to more satisfying choices. It combines monthly online reports of the various persons (including the PA) who had been consulted regarding one's major choice and of current indecision regarding one's choice with ratings of choice satisfaction and evaluations of the participant's PA as a 
collaborator during decision making. We explicitly focused on collaboration as the kind of involvement through which a PA should be most helpful to students choosing a major, because it reflects the most welcome, direct, and active role that another person may play (Berg \& Upchurch, 2007). Collaboration or joint action has only started to receive research attention in real-life studies on career development and decision making (e.g., Chang et al., 2010; Marshall et al., 2008; Phillips et al., 2001; Schultheiss et al., 2001). We intended to show that considering work on collaboration that originated outside the career development area (cf. Berg \& Upchurch, 2007) is useful in determining how to best assist students during decision making. The central aim of our research was to investigate under which conditions involving one's PA in choosing a major was related to greater choice satisfaction. Rather than presuming that a PA usually is involved and that this benefits the individual, we sought to understand when the PA is involved and whether evaluations of the PA as a collaborator influence the potential benefits of his or her involvement.

\subsection{Preferred Partners for Decision Making, Advice Giving, and Problem Solving}

While extant literature offers information on the people who typically are involved when people make career decisions (Phillips et al., 2001; Schultheiss et al., 2001) or try to cope with a personal problem more generally (Feng \& MacGeorge, 2010; Strough, Patrick, Swenson, Cheng, \& Barnes, 2003), it does not tell us whether someone among those people would be considered the PA. We know that a vast majority of people like to consult with others when they need to make major life decisions (Heath \& Gonzalez, 1995). For instance, $86 \%$ of the respondents in Phillips et al. (2001) described that they had actively recruited the help of others in making career choices. Depending on the respondent's age, the involved social partners varied somewhat, but typically included family members, spouses and significant others, friends and acquaintances, or professional contacts like counselors, teachers, and coworkers (Phillips et al., 2001; Schultheiss et al., 2001). However, only one study has asked older participants to identify their preferred partner for collaborative everyday problem solving (Strough et al., 2003). While spouses typically were preferred, chosen partners were not limited to spouses. Thus, we cannot presuppose who is the best or preferred collaborator for a given individual. Rather, the selection of a PA can be expected to vary depending on the relationship partners potentially available to the individual. By focusing on the PA as the preferred relational resource, we hoped to capture the diversity both in PAs and in the quality of support and guidance that they can offer.

Nevertheless, we cannot expect that this preferred resource would be drawn upon during every decision. Rather, involvement of one's PA as well as others more generally depends on the perception of a specific decision. First, the PA may be consulted because the decision maker does not feel competent to arrive at a choice. Indeed, indecision, uncertainty, decision difficulties, or lack of faith in one's decision-making ability have been related to involving others in decision making (cf. Bonaccio \& Dalal, 2006; Phillips et al., 2001; Schultheiss et al., 2001). We thus hypothesized that indecision regarding one's choice of major would be related to involving one's PA (Hypothesis 1).

Second, the individual may think that this particular decision is not his or her sole responsibility but affects the PA as well. Extant research underscores that even decisions, problems, or projects where "ownership" has traditionally been presumed to lie with one person, in fact, often are perceived as shared with others (cf. Berg \& Upchurch, 2007; Salmela-Aro \& Little, 2007). This also applies to youths or emerging adults and their parents, who often work together on tasks and decisions during the transition to adulthood (Marshall et al., 2008; Young et al., 2008) and during educational transitions and challenges more specifically (Chang, Heckhausen, Greenberger, \& Chen, 2010; Dietrich et al., 2011).

Nevertheless, it also has been shown that collaboration does not always lead to better outcomes. Rather, both adolescents (Berg et al., 2009) and older people (Schindler, Berg, Butler, Fortenberry, \& Wiebe, 2010) benefitted from collaboration only when they shared problems or goals with their collaborator, but did not benefit or even suffered from collaboration when problems or goals were theirs alone. The research presented in this paper seeks to complement those findings by addressing the question of when involvement of a PA is beneficial or not. However, we investigated specific dimensions of collaboration with the PA that may function to increase choice satisfaction rather than perceptions of the decision as shared.

\subsection{Functions of Collaboration in Decision Making and Problem Solving}

Our primary research interest was in cases where the individual would actively seek out his or her PA as one way to adequately engage in the major choice process (cf. Dietrich et al., 2012). Therefore, we focused on collaboration (rather than the broad construct of social support) as a specific kind of involvement that best captures how both student and PA actively participate in reaching a decision (cf. Berg \& Upchurch, 2007). Collaboration means that the individual works together with another person when generating alternatives, 
gathering and evaluating information, and figuring out a best choice rather than just receiving emotional or instrumental support during individual decision making.

During collaboration, career choice becomes a joint project between student and PA (see also Young et al., 2008). It should be noted that our notion of collaboration is different from collaboration as described by Phillips et al. (2001). That is, collaboration does not necessarily mean to consider how the decision affects the PA and to make a choice that benefits him or her as well, but rather to jointly engage in decision making regardless of whether all involved parties benefit from the choice outcome. Collaboration as used here rather can be viewed as an expression of mutuality (Josselson, 1996), the relational dimension of emotionally being with another and together creating something greater than each individual's contribution. As advocated by Flum (2001), mutuality is one relational experience worth considering in studies of career development, as it, among other things, can provide an arena for vocational exploration.

Prior research has identified different dimensions of collaboration (e.g., Berg, Schindler, \& Maharajh, 2008), which also reflect specific benefits that collaboration can offer. These benefits involve cognitive ones (compensation for expertise the decision maker does not have or optimizing decision quality), compensating for lack of motivation, and creating interpersonal enjoyment.

With regard to cognitive benefits of collaboration, familiarity of the collaborators plays an important role. Intimate knowledge of one's collaborator along with a history of working together is crucial to collaborative gains (cf. Johansson, Andersson, \& Rönnberg, 2000; Wegner, Erber, \& Raymond, 1991). However, advisors also can contribute to better decisions in other ways (cf. Bonaccio \& Dalal, 2006). They can provide information and expertise that the individual does not have, they tend to conduct a more balanced information search than the decision maker him- or herself (Jonas \& Frey, 2003), and they help to increase confidence in the decision (Heath \& Gonzalez, 1995). The latter may be crucial with real-life decisions where there is no objectively best choice but it still is important to act with confidence when implementing one's choice (cf. Savickas, 2005).

In addition to cognitive benefits, collaboration can foster engagement in decision making. Career-related and other real-life decisions often require sustained engagement in collecting and evaluating information, which can be supported by relationship partners (cf. Dietrich et al., 2012). In line with this assumption, supportive involvement of parents in youths' career-related decisions was linked to youths' greater career exploration and goal engagement (Dietrich et al., 2011; Dietrich \& Salmela-Aro, 2013).

Finally, collaboration not only serves to enhance performance but also to enhance relationship quality between the collaborators if it is perceived as an enjoyable joint activity (also see Josselson, 1996, on mutuality and resonance). It has been shown that collaboration is more likely to take place (Bodenmann, Pihet, \& Kayser, 2006; Hagedoorn, Kuijer, Buunk, DeJong, Wobbes, \& Sanderman, 2000) and more effective when it takes place (Berg, Johnson, Meegan, \& Strough, 2003) in the context of a satisfying and accepting relationship. People further are more likely to utilize advice from trusted and liked advisors (cf. Bonaccio \& Dalal, 2006). Interaction with an advisor who is liked and is perceived as similar to oneself also has been found to facilitate coping with upsetting real-life problems (Feng \& MacGeorge, 2010).

In light of the above considerations, we predicted that the mere involvement of one's PA during major choice is unrelated to choice satisfaction (Hypothesis 2a). Rather, we expected that only the involvement of a high quality PA would benefit choice satisfaction. Specifically, we hypothesized that both qualitative (open responses concerning why the PA is preferred; Hypothesis 2b) and quantitative (ratings of dimensions of collaboration; Hypothesis 2c) evaluations of the PA as collaborator moderate the association between involvement of the PA and choice satisfaction. Only when the PA is perceived as highly familiar with the individual, able to improve decision quality, needed to keep the individual engaged in decision making, or a liked collaborator should turning to him or her for assistance contribute to a satisfying choice.

\section{Method}

\subsection{Participants and Procedure}

Our data stem from a longitudinal study (up to one year) on choices of college majors and romantic partners. The parent sample includes 149 students at a university (94\%) or college (6\%) in the Western United States, who had been recruited through mass e-mails. As our focus is on major choice, we considered only students who had reported on choosing a major.

Participants first completed a 90-minute intake assessment at our lab, which took place some time between August 2006 and April 2007. Subsequently, participants filled out repeated assessments during each month of the study until August 2007 asking about their major choice. These assessments were done online and took up to 
30 minutes to complete. Once participants had decided on a major, they completed monthly online assessments following up on their choice satisfaction and potential choice reversals. A 60-minute final assessment conducted at our lab some time between August and October 2007 included questions on the PA. Participants received a monetary compensation of $\$ 10$ for each 60-90 minutes of testing. Between the intake and final assessments, 47 people (31.5\% of the sample) dropped out of the study.

The present analyses include participants in the major choice part of the study who completed the final assessment. The resulting sample consists of 65 students between 18 and 27 years, $M=21.0, S D=2.0$, of whom $53.8 \%$ were women. At the intake assessment, this sample included $23.1 \%$ college freshmen, $32.3 \%$ sophomores, $43.1 \%$ juniors, and one senior $(1.5 \%)$. As is representative of the area where the study was conducted, participants were predominantly Caucasian $(89.2 \% ; 10.8 \%$ of Hispanic or Asian descent or multiracial). Initially, 37 students were undecided on their major and 28 were decided but considering to change their major. During the study interval, which ranged between 4 and 13 months, $M=9.1$ (due to varying timing of the intake assessment and a fixed end date for the study), we collected between 2 and 12 monthly online assessments per participant, $M=7.6$. Specifically, each participant provided between 1 and 10 assessments, $M=2.9$, relevant to choosing (0-10 assessments, $M=1.9)$ and/or changing (0-6 assessments, $M=1.0)$ a major, which included data on the people who were consulted during decision making. In addition, we collected between 0 and 11 assessments, $M=4.7$, during months when participants were decided on a major and did not consider changing majors, which included data on choice satisfaction. By the end of the study, 28 of the initially undecided students had chosen a major. Of the 28 decided students considering a change of major, 23 stuck with their major and 5 changed. Thus, the majority of participants $(86.2 \%)$ had decided on a major before the final assessment, but 9 participants (13.8\%) still were undecided. Considered and chosen majors come from a range of fields, including social and natural sciences, engineering, teaching, languages, and political science.

\subsection{Measures}

All measures were checked for outliers. Univariate outliers (between 0 and 2 participants per measure) were assigned the smallest or largest value that did not produce an outlier.

\subsubsection{Monthly College Major Assessments}

During each month of the study, participants completed an online assessment. Undecided students identified one or two majors that they currently preferred the most and indicated whether they had decided on one of these majors in the meantime. They then answered questions regarding their evaluation of the one or two listed majors and their decision-making process. Participants who reported to have chosen a major were scheduled to fill out the assessment for decided students during the next month.

Decided students were asked whether they had reversed their major choice during the last month or whether they considered changing their major. Regardless of their response to these questions, participants answered several questions on how they evaluate their (formerly) chosen major, including choice satisfaction. Participants who had opted out of their formerly chosen major or considered a change of major answered additional questions at the end of the assessment. They listed either their newly chosen major or the alternative major that they currently preferred the most. Participants then evaluated this new or alternative major and reported on their decision-making process.

\subsubsection{Involvement of Others in Major Choice}

As part of each assessment for undecided students, participants thought about the last month and responded to the question "Was there anyone who was somehow involved in your deciding on this major?" Those who answered "yes," could list up to 5 involved persons. These questions were repeated with regard to the second-most preferred major. Students who considered a change of major responded to the same set of questions with regard to their preferred alternative or newly chosen major.

When combining responses across all majors and assessments, we found that the reported involvement of others varied considerably. On average, at least one other person was involved in deciding on a major in $44.5 \%$ of the collected monthly decision-making assessments. Between participants, this percentage varied from $0 \%$ to $100 \%$. Those 43 participants who reported some involvement listed between 1 and 13 different persons across all assessments, $M=3.5$. Most of the 149 persons nominated in total were close relationship partners $(10.9 \%$ mother, $10.2 \%$ father, $6.8 \%$ siblings, $6.1 \%$ other family members, $7.5 \%$ current romantic partners, and $25.2 \%$ friends). Participants further involved counselors, mentors, professors, or teachers $(21.1 \%)$, former romantic partners and (ex-) partners' family members $(5.4 \%)$, acquaintances $(4.1 \%$, e.g., other students, co-workers, roommates), and bosses or professional contacts $(2.7 \%)$. 


\subsubsection{Indecision regarding Major Choice}

Participants responded to the statement "I am indecisive about whether to choose this major or not" on a 6-point scale (1 "not true of me" -6 "exactly true of me"). Undecided students provided two indecision ratings for the most and second-most preferred majors. Decided students who changed majors (or considered it) provided one indecision rating for the (preferred) new major. Indecision ratings were averaged across majors and assessments, $M=3.63, S D=1.38$.

\subsubsection{Satisfaction with Major Choice}

Decided students' satisfaction with their chosen major was measured with four items (6-point scale: 1 "not very much" -6 "very much"), $\alpha=.93$. An exemplary item is "How satisfied are you with your choice of major?" Responses were averaged across items and assessments after the decision. For those participants who considered changing their major but did not do so in the end, choice satisfaction was computed by averaging satisfaction ratings across all assessments that were collected after the student had indicated that he or she considers a change of major for the last time in the study. On average, our participants were satisfied with their choices, $M=$ $5.03, S D=0.69$. It should be noted that satisfaction data are available for only 48 of the 65 participants. Missing satisfaction data are due to participants still being undecided at the end of the study or to students reporting a choice on their last online assessment so that satisfaction could not be measured a month later.

\subsubsection{Final Assessment}

The final assessment included a section asking participants "to think about whether and how you involve other people when you need to make important decisions, such as deciding on a college major or making decisions regarding a romantic partner." Participants nominated a PA, gave a reason for this choice, and rated their perceptions of collaboration with the PA.

\subsubsection{Preferred Advisors}

Participants first answered the question "When you need to make important decisions, is there anyone you would seek out or get involved?" Only $4(6.2 \%)$ of the 65 participants said that they would not involve anyone. Those who had stated that they would involve someone identified the person they would most likely seek out. The 61 PAs included the participant's mother $(23.0 \%)$, father $(19.7 \%)$, sibling $(9.8 \%)$, other family member $(3.3 \%)$, current romantic partner $(26.2 \%)$, or a friend $(18.0 \%)$.

\subsubsection{Reasons for Choice of Preferred Advisor}

Participants wrote down their response to the open-ended question "Why would you go to this person?" One participant did not respond to this question. The 60 answers given consisted of short statements including between 5 and 48 words, $M=15.8$. The first author segmented the responses into smallest meaningful units for coding (1-6 segments per participant, $M=2.4)$ and developed a coding scheme including four different codes. The first and second author performed an independent coding of all segments, $\mathrm{K}=.92$. In our analyses, we only included the first three codes, because code 4 interdependence was rare (10\% of the participants) and limited to romantic partners as the PA.

Code 1 familiarity was applied for responses referring to the PA's intimate knowledge of or similarity to the participant (i.e., the PA knows everything that is important to know about the participant). This code includes references to relationships (e.g., "she's my mother") that imply a high level of familiarity. Exemplary segments coded as "1" include "because I've known her for 10 years," "he knows me better than anyone," or "she is much like me in ways of thinking."

Code 2 positive relationship quality was applied when participants referred to characteristics of the PA that make interacting with him or her enjoyable, to their positive overall relationship quality with the PA, or to the PA having the student's best interest at heart. Examples include "because she cares for me," "to seek comfort," or "I trust her."

Code 3 decision improvement includes references to the better quality of the resulting decision when collaborating with the PA due to the advisor's life experience, knowledge, or his or her compensating for some of the student's limitations in decision making. Exemplary segments are "has always given good advice," "wise," or "to bounce ideas off her."

The codes were aggregated to form three variables reflecting whether the participant had obtained codes 1 to 3 for at least one segment or not ( 0 "no," 1 "yes"). Forty percent received code 1 familiarity, $M=0.40, S D=0.49$, $41.7 \%$ received code 2 positive relationship quality, $M=0.42, S D=0.50$, and $78.3 \%$ received code 3 decision improvement, $M=0.78, S D=0.42$. 


\subsubsection{Perceptions of Collaboration with Preferred Advisor}

We developed an extended and revised version (PCQ-E; see Appendix) of the Perceptions of Collaboration Questionnaire (PCQ; Berg et al., 2008). This measure includes five dimensions of collaboration (i.e., cognitive optimization and motivational compensation as new dimensions to complement the original PCQ dimensions of frequency, cognitive compensation, and interpersonal enjoyment), which are rated on a 5-point scale (1 "strongly disagree" -5 "strongly agree"). The first dimension measures the perceived frequency of collaborative decision making between the participant and the PA ( 4 items, $\alpha=.80$ ). The cognitive optimization scale measures the extent to which the participant believes that an optimal decision results when working together with his or her PA (4 items, $\alpha=.80$ ). The cognitive compensation scale reflects that the PA is needed to make up for own cognitive limitations ( 3 items, $\alpha=.63$ ). The motivational compensation scale assesses the extent to which the PA is needed to keep working on the decision and its implementation ( 3 items, $\alpha=.68$ ). The interpersonal enjoyment scale measures benefits of collaboration to the relationship between student and PA ( 3 items, $\alpha=.62)$. A confirmatory factor analysis (see Appendix) showed that the expected 5-factor structure yielded an adequate fit to the PCQ-E data, which was superior to the fit of an alternative model including only one overall collaboration factor. Scale scores were computed as the mean across the respective items, frequency, $M=3.24$, $S D=0.93$; cognitive optimization, $M=3.87, S D=0.66$; cognitive compensation, $M=3.50, S D=0.84$; motivational compensation, $M=2.06, S D=0.67$; interpersonal enjoyment, $M=4.09, S D=0.56$.

\subsubsection{Involvement of Preferred Advisor during Prior College Major Choice}

Based on all monthly assessments relevant to choosing and changing majors, we determined whether someone of the listed involved persons was the PA. Of the $61 \mathrm{PAs}, 36.1 \%$ had been involved in the prior college major decision. We created a grouping variable differentiating between students who had not involved anyone across all decision assessments, $n=22$, students who had involved other people but not their PA, $n=21$, and students who had involved their PA (and often other people as well), $n=22$. For our analyses, we formed a variable differentiating between the first two groups (coded 0 ) and the group who had involved their PA (coded 1).

\section{Results}

Our first research interest concerned differences between people who had or had not involved their PA during their recent college major choice. In line with Hypothesis 1, greater indecision regarding one's major choice was positively correlated with involvement of the PA, $r=.28, p<.05$. We further found that involvement of one's PA was unrelated to all other study variables, $r$ s between -.13 and .20 , all $n s$.

Our second research interest concerned the potential benefits of involving one's PA for choice satisfaction. In line with our expectation (Hypothesis 2a), involvement of the PA per se was unrelated to choice satisfaction, $r=$ $-.10, n s$. We thus considered our qualitative and quantitative data on evaluations of the PA to determine whether the perceived quality of the PA moderated the relationship between involvement and satisfaction.

As our sample was small, it was important to limit the number of predictors in each regression. Therefore, we included only one code or one PCQ-E scale in each regression. We further determined whether we needed to control for type of relationship with the PA (family/friend vs. romantic partner), number of segments provided for coding (where codes were included), or number of completed decision assessments in our regressions. As all these control variables failed to reach significance and did not affect the remaining findings we chose to conduct our regressions with the smallest possible set of predictors.

We further guarded against two problems that are likely to occur when analyzing small samples. First, we searched for influential multivariate outliers by inspecting Cook's distances and found one outlier in regressions including the qualitative codes and two outliers in regressions including the PCQ-E scales. As inspection of these participants' data confirmed that they differed markedly from the observed pattern among the remaining participants, they were excluded from the respective analyses. Second, we wanted to make sure that we were not overfitting our data and thereby producing spurious findings. We thus corroborated our findings by obtaining bootstrap estimates of the parameter estimates based on 5,000 bootstrap samples drawn with replacement from our original sample. We report the bias-corrected bootstrap 95\% confidence interval (BC 95\% CI). Finally, we based our regressions on all available data in our sample by running the regressions in Mplus Version 6.1 (Muthén \& Muthén, 1998-2010), which handles incomplete data by utilizing all available observations to compute full information maximum likelihood parameter estimates. Except for the dichotomous variables, predictors were centered at their mean prior to computing interaction terms and inclusion in the regressions.

\subsection{Reasons for Selecting the Preferred Advisor}

We ran three regressions to determine associations of involvement of the PA and reasons for selecting this PA 
with choice satisfaction. Each regression included four predictors: Indecision (as a control variable related to choice satisfaction and involvement), involvement of the PA $(0=$ no, $1=$ yes $)$, one of the three codes reflecting reasons for selecting the PA (received code: $0=$ no, $1=$ yes), and the interaction between involvement and obtaining a code.

As can be seen in Table 1, greater indecision was associated with lower satisfaction with one's major choice in all three regressions. Neither the mere involvement of the PA nor receiving a code or not had a direct effect on choice satisfaction. However, in partial support of Hypothesis $2 b$, there was one significant interaction between involvement of the PA and receiving code 1 familiarity, $B=1.04, p<.05, \Delta R^{2}=.08$. This interaction remained significant when running the bootstrap analysis, as indicated by zero not being included in the BC $95 \% \mathrm{CI}$. To further probe this interaction, we employed an online tool described by Preacher, Curran, and Bauer (2006). As illustrated in Figure 1 (Panel A), involvement of the PA was unrelated to choice satisfaction when familiarity (code 1) was not given as a reason for selecting this PA, simple slope $B=-0.10, t(59)=-0.44, n s$. In contrast, involvement of the PA was associated with greater choice satisfaction when the PA was preferred because of his or her familiarity with the student, simple slope $B=0.94, t(59)=2.22, p<.05$. The predicted interaction (Hypothesis $2 \mathrm{~b}$ ) between involvement and reasons for preferring the advisor was not obtained with code 2 positive relationship quality and code 3 decision improvement.

Table 1. Predicting satisfaction with major choice from preferred advisor's choice involvement and reasons for preferring advisor

\begin{tabular}{|c|c|c|c|c|c|c|c|c|c|c|c|c|}
\hline \multirow[b]{4}{*}{ Predictor } & \multicolumn{12}{|c|}{ Coding: Why is advisor preferred? } \\
\hline & \multicolumn{4}{|c|}{$\begin{array}{l}\text { Familiarity } \\
\text { (Code 1) }\end{array}$} & \multicolumn{4}{|c|}{$\begin{array}{l}\text { Positive relationship quality } \\
\qquad \text { (Code } 2)\end{array}$} & \multicolumn{4}{|c|}{$\begin{array}{c}\text { Decision improvement } \\
\text { (Code } 3)\end{array}$} \\
\hline & \multirow[b]{2}{*}{$B$} & \multirow[b]{2}{*}{$\beta$} & \multicolumn{2}{|c|}{$\mathrm{BC} 95 \% \mathrm{CI}$} & \multirow[b]{2}{*}{$B$} & \multirow[b]{2}{*}{$\beta$} & \multicolumn{2}{|c|}{$\mathrm{BC} 95 \% \mathrm{CI}$} & \multirow[b]{2}{*}{$B$} & \multirow[b]{2}{*}{$\beta$} & \multicolumn{2}{|c|}{$\mathrm{BC} 95 \% \mathrm{CI}$} \\
\hline & & & LL & UL & & & LL & UL & & & LL & UL \\
\hline 1 Intercept & $4.99 * * *$ & & 4.68 & 5.22 & $5.00^{* * *}$ & & 4.77 & 5.22 & $5.27 * * *$ & & 4.86 & 5.58 \\
\hline 2 Indecision & $-0.25 * * *$ & $-.51 * * *$ & -0.39 & -0.13 & $-0.23 * * *$ & $-.46^{* * *}$ & -0.38 & -0.10 & $-0.21 * *$ & $-.43 * *$ & -0.34 & -0.07 \\
\hline $\begin{array}{l}3 \text { PA involved in major choice? } \\
(0=\text { no, } 1=\text { yes })\end{array}$ & -0.10 & -.07 & -0.62 & 0.41 & -0.08 & -.05 & -0.64 & 0.50 & 0.25 & .18 & -0.19 & 0.76 \\
\hline $\begin{array}{l}4 \text { Received code? } \\
(0=\text { no, } 1=\text { yes })\end{array}$ & -0.04 & -.03 & -0.41 & 0.40 & -0.05 & -.03 & -0.52 & 0.37 & -0.35 & -.22 & -0.71 & 0.11 \\
\hline 5 Interaction $3 \times 4$ & $1.04 *$ & $.45^{*}$ & 0.28 & 1.83 & 0.57 & .26 & -0.25 & 1.32 & -0.21 & -.14 & -0.98 & 0.50 \\
\hline$R^{2}$ & $.32 * *$ & & & & $.27^{*}$ & & & & $.27 *$ & & & \\
\hline
\end{tabular}

Note. $N=64$. BC $95 \% \mathrm{CI}=$ bias-corrected $95 \%$ confidence interval for $B$ based on 5,000 bootstrap samples. LL $=$ lower limit of BC $95 \% \mathrm{CI}$. UL = upper limit of BC $95 \% \mathrm{CI}$.

\subsection{Perceptions of Collaboration with the Preferred Advisor}

In our second set of analyses, we ran five regressions including each of the PCQ-E scales (instead of the codes) as predictors of choice satisfaction. The other predictors remained unchanged. We obtained no main effects for involvement of the PA or for ratings of the PA on the PCQ-E scales that were not further qualified by interactions (see Tables 2 and 3). In partial support of Hypothesis 2c, we found three significant interactions between involvement and perceptions of collaboration. Specifically, interactions were found for collaboration frequency, $B=0.51, p<.05, \Delta R^{2}=.12$, cognitive optimization, $B=1.05, p<.05, \Delta R^{2}=.16$, and motivational compensation, $B=0.74, p<.05, \Delta R^{2}=.03$. The interactions between involvement and frequency or, respectively, cognitive optimization remained significant at the .05 level in the bootstrap analyses (see Table 2). In contrast, the interaction between involvement and motivational compensation (Table 3) was reduced to trend-level significance, $p<.10$, when running the bootstrap analysis, as indicated by a $\mathrm{BC} 90 \% \mathrm{CI}$ from 0.08 to 1.61 . The cognitive compensation and interpersonal enjoyment scales did not interact with involvement of the PA in predicting choice satisfaction. 
Table 2. Predicting satisfaction with major choice from preferred advisor's choice involvement and perceptions of collaboration with advisor (first three PCQ-E scales)

\begin{tabular}{|c|c|c|c|c|c|c|c|c|c|c|c|c|}
\hline \multirow[b]{4}{*}{ Predictor } & \multicolumn{12}{|c|}{ PCQ-E scale } \\
\hline & \multicolumn{4}{|c|}{ Frequency } & \multicolumn{4}{|c|}{ Cognitive optimization } & \multicolumn{4}{|c|}{ Cognitive compensation } \\
\hline & \multirow[b]{2}{*}{$B$} & \multirow[b]{2}{*}{$\beta$} & \multicolumn{2}{|c|}{ BC $95 \% \mathrm{CI}$} & \multirow[b]{2}{*}{$B$} & \multirow[b]{2}{*}{$\beta$} & \multicolumn{2}{|c|}{ BC $95 \%$ CI } & \multirow[b]{2}{*}{$B$} & \multirow[b]{2}{*}{$\beta$} & \multicolumn{2}{|c|}{ BC $95 \%$ CI } \\
\hline & & & $\mathrm{LL}$ & $\mathrm{UL}$ & & & LL & UL & & & LL & UL \\
\hline 1 Intercept & $4.95 * * *$ & & 4.70 & 5.18 & $4.98 * * *$ & & 4.76 & 5.18 & $4.99 * * *$ & & 4.79 & 5.19 \\
\hline 2 Indecision & $-0.24 * * *$ & $-.50 * * *$ & -0.36 & -0.09 & $-0.20 * * *$ & $-.42 * * *$ & -0.32 & -0.09 & $-0.21 * * *$ & $-.45 * * *$ & -0.33 & -0.09 \\
\hline 3 PA involved in major choice? & 0.02 & .02 & -0.42 & 0.62 & -0.07 & -.05 & -0.49 & 0.43 & -0.03 & -.02 & -0.55 & 0.49 \\
\hline \multicolumn{13}{|l|}{$(0=$ no, $1=$ yes $)$} \\
\hline 4 PCQ-E scale & -0.15 & -.21 & -0.43 & 0.11 & -0.10 & -.10 & -0.40 & 0.18 & -0.02 & -.03 & -0.29 & 0.17 \\
\hline 5 Interaction $3 \times 4$ & $0.51^{*}$ & $.42 *$ & 0.05 & 0.91 & $1.05^{*}$ & $.47 *$ & 0.08 & 2.22 & -0.23 & -.15 & -0.95 & 0.59 \\
\hline$R^{2}$ & $.33 * *$ & & & & $.36^{* *}$ & & & & $.26^{*}$ & & & \\
\hline
\end{tabular}

Note. $N=63 . \mathrm{BC} 95 \% \mathrm{CI}=$ bias-corrected $95 \%$ confidence interval for $B$ based on 5,000 bootstrap samples. $\mathrm{LL}$

$=$ lower limit of BC $95 \%$ CI. UL $=$ upper limit of BC 95\% CI.

Table 3. Predicting satisfaction with major choice from preferred advisor's choice involvement and perceptions of collaboration with advisor (last two PCQ-E scales)

\begin{tabular}{|c|c|c|c|c|c|c|c|c|}
\hline \multirow[b]{4}{*}{ Predictor } & \multicolumn{8}{|c|}{ PCQ-E scale } \\
\hline & \multicolumn{4}{|c|}{ Motivational compensation } & \multicolumn{4}{|c|}{ Interpersonal enjoyment } \\
\hline & \multirow[b]{2}{*}{$B$} & \multicolumn{3}{|c|}{$\mathrm{BC} 95 \% \mathrm{CI}$} & \multirow[b]{2}{*}{$B$} & \multicolumn{3}{|c|}{$\mathrm{BC} 95 \% \mathrm{CI}$} \\
\hline & & $\beta$ & LL & UL & & $\beta$ & LL & UL \\
\hline 1 Intercept & $4.94 * * *$ & & 4.77 & 5.11 & $5.00 * * *$ & & 4.79 & 5.21 \\
\hline 2 Indecision & $-0.18 * *$ & $-.39 * *$ & -0.28 & -0.08 & $-0.20 * *$ & $-.44 * *$ & -0.33 & -0.08 \\
\hline 3 PA involved in major choice? & 0.08 & .06 & -0.37 & 0.60 & 0.00 & .00 & -0.55 & 0.56 \\
\hline \multicolumn{9}{|l|}{$(0=$ no, $1=$ yes $)$} \\
\hline 4 PCQ-E scale & $-0.51 * * *$ & $-.50 * * *$ & -0.83 & -0.18 & 0.07 & .06 & -0.33 & 0.43 \\
\hline 5 Interaction $3 \times 4$ & $0.74^{*}$ & $.39 *$ & -0.12 & 1.89 & 0.11 & .06 & -0.55 & 0.87 \\
\hline$R^{2}$ & $.40 * * *$ & & & & $.22 *$ & & & \\
\hline
\end{tabular}

Note. $N=63 . \mathrm{BC} 95 \% \mathrm{CI}=$ bias-corrected $95 \%$ confidence interval for $B$ based on 5,000 bootstrap samples. LL

$=$ lower limit of BC $95 \%$ CI. UL $=$ upper limit of BC 95\% CI.

When following up on the three interactions, we found the pattern illustrated in Figure 1. Involvement of the PA was unrelated to choice satisfaction when collaboration frequency was low $(M-1 S D)$, simple slope $B=-0.45, t$ $(58)=-1.60, n s$, or average $(M)$, simple slope $B=0.02, t(58)=0.12, n s$, but tended to relate positively to satisfaction with frequent collaboration $(M+1 S D$ ), simple slope $B=0.49, t(58)=1.87, p<.10$ (Panel B, Fig. 1). The obtained region of significance revealed that a significantly positive, $p<.05$, relationship between involvement and satisfaction resulted with frequency scores above 4.33 .

We obtained a similar and even more pronounced finding with the cognitive optimization scale (Panel C, Fig. 1). Involvement of the PA tended to relate to lower choice satisfaction with low cognitive optimization scores, simple slope $B=-0.76, t(58)=-1.99, p<.10$. With average cognitive optimization this relationship was nonsignificant, simple slope $B=-0.07, t(58)=-0.35, n s$, but tended to become positive when cognitive optimization was high, simple slope $B=0.62, t(58)=1.99, p<.10$. Based on the region of significance, a 
significantly negative involvement-satisfaction relationship resulted with cognitive optimization scores below 3.19 and a significantly positive relationship resulted when cognitive optimization was above 4.54.

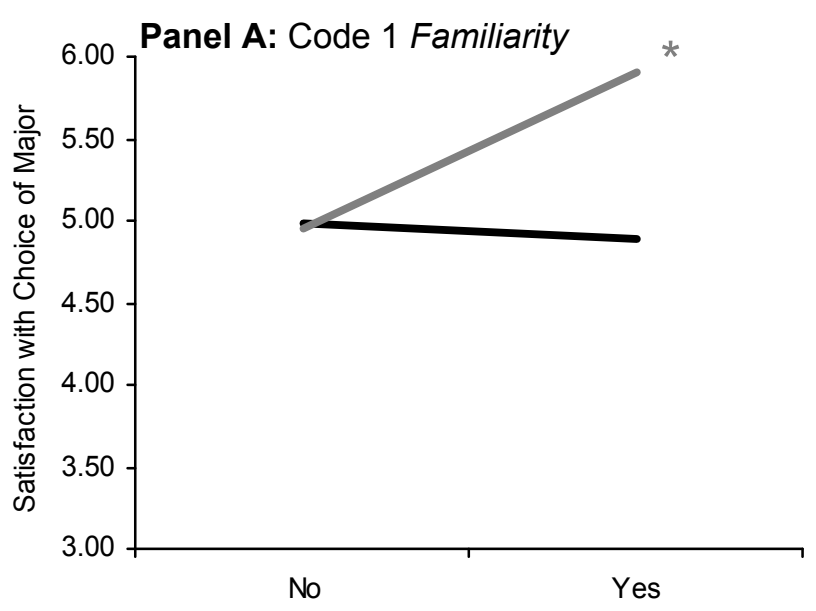

Preferred Advisor Involved?

\section{Received Code 1?}

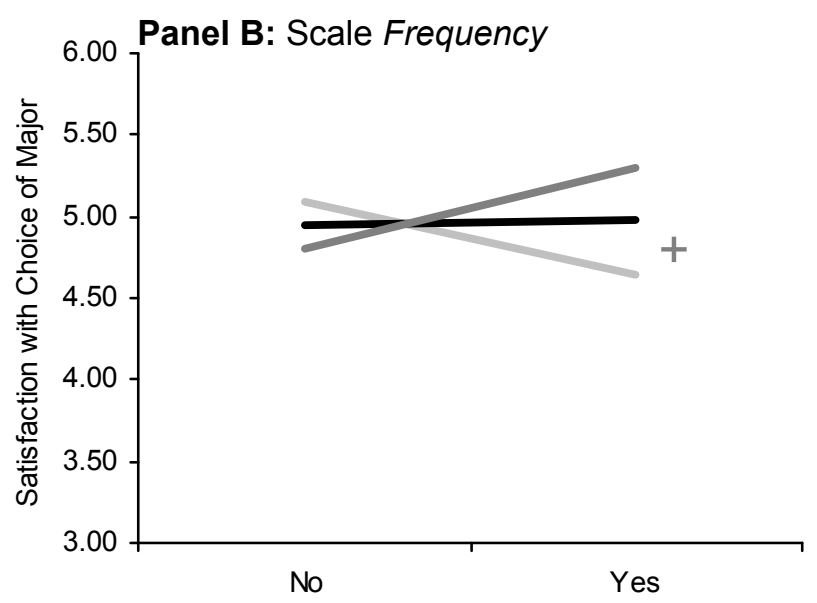

Preferred Advisor Involved?

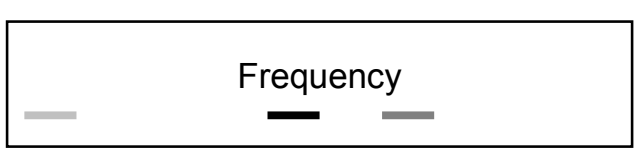

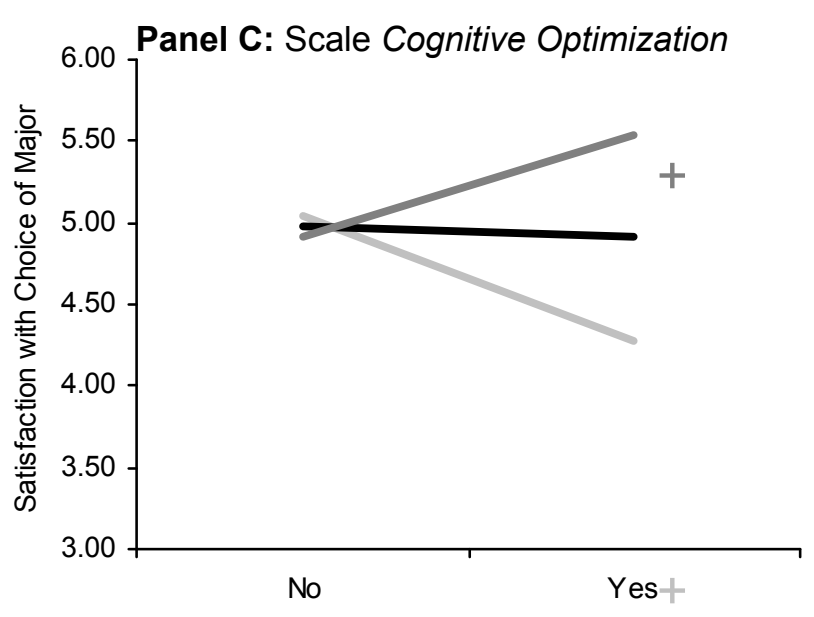

Preferred Advisor Involved?

Cognitive Optimization

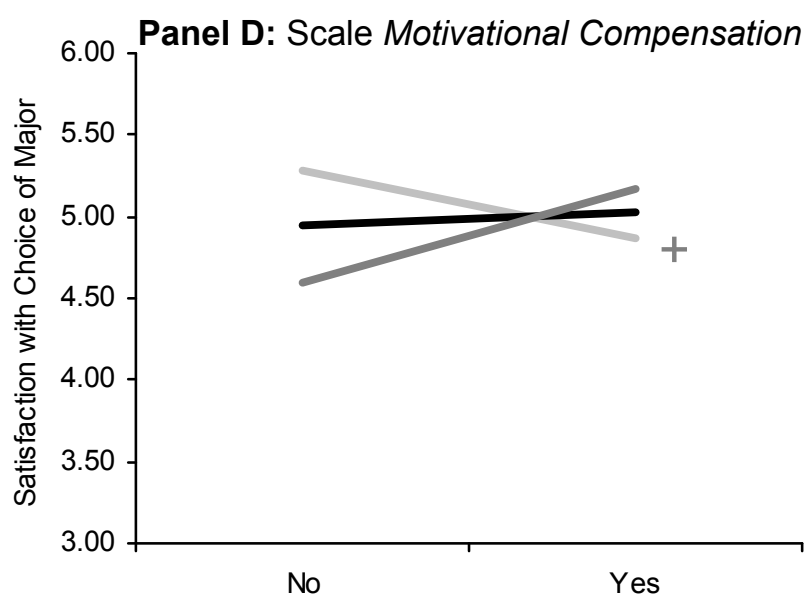

Preferred Advisor Involved?

Figure 1. Interactions of involvement of the preferred advisor in major choice with familiarity as a reason for preferring the advisor (Panel A) and three PCQ-E scales (Panels B-D) in predicting choice satisfaction

* Simple slope significant at $p<.05$. + Simple slope significant at $p<.10$. 
The final (marginally significant) interaction revealed that involvement of the PA was unrelated to choice satisfaction when motivational compensation was low, simple slope $B=-0.42, t(58)=-1.44, n s$, or average, simple slope $B=0.08, t(58)=0.46, n s$, but tended to relate positively to satisfaction when motivational compensation was high, simple slope $B=0.58, t(58)=1.99, p<.10$ (Panel D, Fig. 1). The region of significance showed that the involvement-satisfaction relationship was nonsignificant with low scores on the motivational compensation scale, but became significantly positive when motivational compensation was above 2.74 .

\section{Discussion}

This study tracked students' progress with college major choice and examined the potential benefits of involving their PAs in this decision, which allowed us to address two questions: First, when do students involve their PA in an actual decision? Second, under which conditions is involving the PA beneficial for choice satisfaction?

Regarding the first question, students were more likely to involve their PA in decision making when they were uncertain about their major (Hypothesis 1). This result matches with qualitative findings by Schultheiss et al. (2001) showing that young people sought the support of others when they found their career decision to be difficult. It further parallels the finding that greater advice seeking is related to greater indecision (Bonaccio \& Dalal, 2006).

With regard to the second question, the results lend some support to our Hypotheses 2a to 2c, which proposed that involvement of the PA during major choice would only be beneficial to choice satisfaction when the PA is perceived as an effective collaborator. However, our findings were mixed: Not all reasons for (Hypothesis $2 b$ ) and perceptions of (Hypothesis 2c) collaboration moderated the relationship between involvement and satisfaction.

Specifically, involvement of the PA per se was unrelated to choice satisfaction (Hypothesis 2a). However, choice satisfaction was higher when an involved PA was preferred because of his or her familiarity with the student (Hypothesis 2b) or very frequently collaborated with the student in making life decisions (Hypothesis 2c). Collaborative gains in career decision making were thus particularly likely when there was a history of making decisions together and when the PA knew the student well (see Johansson et al., 2000; Wegner et al., 1991, for similar findings with other forms of collaboration). This finding further is in line with research demonstrating that interactions with unfamiliar others do not lead to better decisions (Heath \& Gonzalez, 1995).

Involving a PA who was evaluated high on the cognitive optimization function similarly was associated with greater choice satisfaction. If collaboration with the PA was perceived as highly instrumental in finding the best solution to a problem, and if this advisor was involved, students' choice satisfaction was highest. As Phillips et al. (2001) showed, students may draw on other people to help them evaluate alternatives and to select a major, or they may explore choice-related information together to improve their decision (see also Dietrich et al., 2011).

In contrast to the cognitive optimization function, we did not find the expected effects for the qualitative code 3 decision improvement. Due to the small sample size, it would be premature to conclude that interactions between code 3 (and also code 2) and involvement of the PA do not exist. Nevertheless, our findings reveal that familiarity (code 1) was more influential in our sample than decision improvement and positive relationship quality. We think that decision improvement may be the default answer when asked why someone would be involved in decision making ( $78 \%$ of our participants gave this reason). The decision improvement code thus may not be suited to distinguish the best from merely average PAs.

Our results further showed that involvement was related to satisfaction only when motivational compensation scores were high. Individuals who perceived their PA as necessary to provide motivation for decision making were less satisfied with their choice than the other participants when they had not involved this PA, but equally satisfied when they had involved him or her. As this interaction effect decreased to marginal significance in the bootstrap analysis, it needs to be interpreted with caution and warrants replication. It further is noteworthy that we did not obtain a similar finding for the cognitive compensation function, which may be expected to have comparable effects. It may be the case that PAs are sought out to fulfill only some functions of collaboration rather than the full spectrum.

Finally, the relational functions of the PA (code 2 positive relationship quality and the interpersonal enjoyment dimension) did not moderate the involvement-satisfaction link. It may be the case that a positive relationship with one's PA is a necessary basis for effective collaboration or advice utilization (see Berg et al., 2003; Bonaccio \& Dalal, 2006; Feng \& MacGeorge, 2010), but not sufficient. That is, if the relational functions are not combined with the PA's intimate knowledge of the student and rich life experience, collaborating with the PA 
does not lead to a better decision outcome. However, relational functions may offer benefits not studied here, such as increasing satisfaction with the decision making process (rather than the outcome; Dietrich et al., 2011). Moreover, that working together is perceived to enhance relationship quality between the collaborators certainly is a benefit of its own.

\subsection{Limitations}

In addition to the small sample size acknowledged earlier, this study is subject to some limitations. First, as several participants were very close to choosing a major, we often could collect only one pre-choice assessment. There further were students who decided on their major only at the end of the study, thus providing only one post-choice assessment. We thus had to collapse data across all pre-choice assessments and, respectively, across all post-choice assessments, because data were too sparse to allow for longitudinal analyses tracking changes in involvement of the PA and indecision during decision making or in post-choice satisfaction. Future studies should attempt to follow decision-making processes during a longer time span in a larger sample to enable such longitudinal analyses. This may help address important questions, such as whether indecision indeed occurs prior to involvement of one's PA.

Second, the functions of collaboration and the reasons for collaborating with the PA were collected after participants had made their college major choice. We therefore cannot rule out the possibility that recent collaborative experiences with the PA while choosing a major influenced evaluations of the PA rather than the other way round. However, the fact that average evaluations of involved and non-involved PAs did not differ on any of the coded reasons for choosing this PA, ts (58) between 0.15 and $0.98, p$ s between .33 and .88 , or PCQ-E scales, $t \mathrm{~s}(59)$ between 0.39 and $1.58, p$ s between .12 and .70 , speaks against this possibility.

Third, we cannot rule out that PAs who were not mentioned on the assessments had been involved in choosing a major prior to the study. However, if this were the case, these advisors might not have been true collaborators on this particular choice. Otherwise, we would have expected the participant to at least inform such an important collaborator of the choice to be made, which would have manifested in involving this person shortly before the final choice.

Fourth, we studied only one outcome (decision satisfaction after the choice) to assess the potential benefits of involving the PA. It is likely that involvement of the PA per se or specific dimensions of collaboration relate to other outcomes. For example, for 11 participants we obtained ratings of satisfaction with how they go about choosing a major both during months when the PA had and when he or she had not been involved. In spite of this small sample, we found that process satisfaction was greater during months when the PA had been involved, $M=4.06, S D=1.33$, rather than not involved, $M=2.94, S D=1.23, t(10)=3.37, p<.01$. This beneficial effect may well be attributable to relational aspects of collaboration, which have been found to help alleviate stress and increase satisfaction during vocational decision making (Dietrich et al., 2011).

Fifth, this study involved students who had not yet decided on their major and students who considered changing majors. As the respective subsamples were too small, we could not test for differences between these two groups. While we would not expect our findings to differ between students choosing a major for the first, second, or third time, it would have been informative to address this possibility.

\subsection{Conclusion and Implications for Practice}

In spite of these limitations, we believe that it is fruitful to consider collaboration with close others in future studies on real-life decisions. It should be interesting to determine whether similar findings can be obtained with other career-related decisions or decisions in other areas. It may further be informative to determine under which circumstances advisors who are preferred in general are not included in actual decisions - our finding showing a greater likelihood of involving the PA when one is indecisive points to an important role of such advisors especially with difficult decisions.

It may also be fruitful to consider functions of collaboration and PAs during counseling. This study provided additional evidence that collaboration serves different functions. It should have merit to consider that these functions can be targeted to different advisors. For instance, we found that the cognitive compensation function was of little importance with PAs, as it did not relate to choice satisfaction. However, as cognitive compensation means making up for knowledge deficits regarding the current decision, this function may be targeted to experts in the respective domain, such as university counselors or professors. It would be interesting to determine whether different dimensions of collaboration prove most beneficial with different advisors. It is likely that professional counseling, clearly a collaborative endeavor, is sought to obtain collaborative benefits that PAs or other relationship partners do not offer. 
It further may have merit to consider PAs during counseling, because they can fulfill functions that are not easily met by professional counselors. Whereas counselors possess expert knowledge on the world of work and can also establish a positive relationship with their clients, they do not have the sort of intimate knowledge of their client reflected in our familiarity code and the frequency of collaboration dimension. In contrast, involved PAs can increase choice satisfaction especially if they possess intimate knowledge of the decision maker and are experienced in collaborating with him or her. High quality PAs thus may offer important advice that might go unnoticed when consulting with less close and familiar advisors. Thus, future research on collaboration with close relationship partners during decision making may reveal mechanisms to improve decision making that are specific to non-professional counseling contexts.

Finally, counselors could train individuals in recognizing and making use of high quality PAs, but also in avoiding unhelpful advisors. Indeed, our findings suggest potential detrimental effects of turning to a PA when this person is evaluated as a rather poor resource for optimizing decisions. Where possible and available, high quality PAs also could be directly involved in career-based interventions and counseling.

\section{Acknowledgements}

Ines Schindler is now at the Cluster "Languages of Emotion," Free University Berlin, Germany. Julia Dietrich is now at the Department of Educational Science, University of Jena, Germany.

This study was conducted at the University of Utah by Ines Schindler, Cynthia A. Berg, and Christopher P. Fagundes and was supported by a research fellowship and research grant (SCHI 985/1-1 + 2-1) of the German Research Foundation (DFG) awarded to Ines Schindler during her stay at the University of Utah. We are grateful to the many student assistants who helped run the study; in particular, we would like to thank Megan Gertsch, Kyle Murdock, Kristina Stuart, Margarita Ramirez, Marvin Whitaker, Reed Dow, Jennifer Smith, and Zachary Leifson. We are very grateful to the students who devoted their time and energy to participating in this study.

\section{References}

Berg, C. A., Johnson, M. M. S., Meegan, S. P., \& Strough, J. (2003). Collaborative problem-solving interactions in young and old married couples. Discourse Processes, 35, 33-58. http://dx.doi.org/10.1207/S15326950DP3501_2

Berg, C. A., Schindler, I., \& Maharajh, S. (2008). Adolescents' and mothers' perceptions of the cognitive and relational functions of collaboration and adjustment in dealing with type 1 diabetes. Journal of Family Psychology, 22, 865-874. http://dx.doi.org/10.1037/a0013641

Berg, C. A., Skinner, M., Ko, K., Butler, J. M., Palmer, D. L., Butner, J., \& Wiebe, D. J. (2009). The fit between stress appraisal and dyadic coping in understanding perceived coping effectiveness for adolescents with type 1 diabetes. Journal of Family Psychology, 23, 521-530. http://dx.doi.org/10.1037/a0015556

Berg, C. A., \& Upchurch, R. (2007). A developmental-contextual model of couples coping with chronic illness across the adult life span. Psychological Bulletin, 133, 920-954. http://dx.doi.org/10.1037/0033-2909.133.6.920

Blustein, D. L. (2011). A relational theory of working. Journal of Vocational Behavior, 79, 1-17. http://dx.doi.org/10.1016/j.jvb.2010.10.004

Bodenmann, G., Pihet, S., \& Kayser, K. (2006). The relationship between dyadic coping and marital quality: A 2-year longitudinal study. Journal of Family Psychology, 20, 485-493. http://dx.doi.org/10.1037/0893-3200.20.3.485

Bonaccio, S., \& Dalal, R. S. (2006). Advice taking and decision-making: An integrative literature review, and implications for the organizational sciences. Organizational Behavior and Human Decision Processes, 101, 127-151. http://dx.doi.org/10.1016/j.obhdp.2006.07.001

Chang, E. S., Heckhausen, J., Greenberger, E., \& Chen, C. (2010). Shared agency with parents for educational goals: Ethnic differences and implications for college adjustment. Journal of Youth and Adolescence, 39, 1293-1304. http://dx.doi.org/10.1007/s10964-009-9488-7

Dietrich, J., Kracke, B., \& Nurmi, J.-E. (2011). Parents' role in adolescents' decision on a college major: A weekly diary study. Journal of Vocational Behavior, 79, 134-144. http://dx.doi.org/10.1016/j.jvb.2010.12.003

Dietrich, J., Parker, P., \& Salmela-Aro, K. (2012). Phase-adequate engagement at the post-school transition. Developmental Psychology, 48, 1575-1593. http://dx.doi.org/10.1037/a0030188

Dietrich, J., \& Salmela-Aro, K. (2013). Parental involvement and adolescents' career goal pursuit during the 
$\begin{array}{llll}\text { post-school transition. } \quad \text { Journal of } & \text { Adolescence, } & 36,128 \text {. }\end{array}$ http://dx.doi.org/10.1016/j.adolescence.2012.10.009

Feng, B., \& MacGeorge, E. L. (2010). The influences of message and source factors on advice outcomes. Communication Research, 37, 553-575. http://dx.doi.org/10.1177/0093650210368258

Flum, H. (2001). Relational dimensions in career development. Journal of Vocational Behavior, 59, 1-16. http://dx.doi.org/10.1006/jvbe.2000.1786

Germeijs, V., \& Verschueren, K. (2009). Adolescents' career decision-making process: Related to quality of attachment to parents? Journal of Research on Adolescence, 19, 459-483. http://dx.doi.org/10.1111/j.1532-7795.2009.00603.x

Hagedoorn, M., Kuijer, R. G., Buunk, B. P., DeJong, G. M., Wobbes, T., \& Sanderman, R. (2000). Marital satisfaction in patients with cancer: Does support from intimate partners benefit those who need it the most? Health Psychology, 19, 274-282. http://dx.doi.org/10.1037/0278-6133.19.3.274

Heath, C., \& Gonzalez, R. (1995). Interaction with others increases decision confidence but not decision quality: Evidence against information collection views of interactive decision making. Organizational Behavior and Human Decision Processes, 61, 305-326. http://dx.doi.org/10.1006/obhd.1995.1024

Johansson, O., Andersson, J., \& Rönnberg, J. (2000). Do elderly couples have a better prospective memory than other elderly people when they collaborate? Applied Cognitive Psychology, 14, 121-133. http://dx.doi.org/10.1002/(SICI)1099-0720(200003/04)14:2<121::AID-ACP626>3.0.CO;2-A

Jonas, E., \& Frey, D. (2003). Information search and presentation in advisor-client interactions. Organizational Behavior and Human Decision Processes, 91, 154-168. http://dx.doi.org/10.1016/S0749-5978(03)00059-1

Josselson, R. (1996). The space between us: Exploring the dimensions of human relationships. Thousand Oaks, CA: Sage.

Kracke, B. (2002). The role of personality, parents and peers in adolescents' career exploration. Journal of Adolescence, 25, 19-30. http://dx.doi.org/10.1006/jado.2001.0446

Marshall, S. K., Young, R. A., Domene, J. F., \& Zaidman-Zait, A. (2008). Adolescent possible selves as jointly constructed in parent-adolescent career conversations and related activities. Identity: An International Journal of Theory and Research, 8, 185-204. http://dx.doi.org/10.1080/15283480802181727

Muthén, L. K., \& Muthén, B. O. (1998-2010). Mplus user's guide (6th ed.). Los Angeles, CA: Muthén \& Muthén.

Phillips, S. D., Christopher-Sisk, E. K., \& Gravino, K. L. (2001). Making career decisions in a relational context. The Counseling Psychologist, 29, 193-213. http://dx.doi.org/10.1177/0011000001292002

Preacher, K. J., Curran, P. J., \& Bauer, D. J. (2006). Computational tools for probing interactions in multiple linear regression, multilevel modeling, and latent curve analysis. Journal of Educational and Behavioral Statistics, 31, 437-448. http://dx.doi.org/10.3102/10769986031004437

Salmela-Aro, K., \& Little, B. R. (2007). Relational aspects of project pursuit. In B. R. Little, K. Salmela-Aro, \& S. D. Phillips (Eds.), Personal project pursuit: Goals, action, and human flourishing (pp. 199-219). Mahwah, NJ: Erlbaum.

Savickas, M. L. (2005). The theory and practice of career construction. In R. W. Lent, \& S. D. Brown (Eds.), Career development and counseling: Putting theory and research to work (pp. 42-70). Hoboken, NJ: Wiley.

Schindler, I., Berg, C. A., Butler, J. M., Fortenberry, K. T., \& Wiebe, D. J. (2010). Late-midlife and older couples' shared possible selves and psychological well-being during times of illness: The role of collaborative problem solving. Journal of Gerontology: Psychological Sciences, 65B, 416-424. http://dx.doi.org/10.1093/geronb/gbq030

Schultheiss, D. E. P., Kress, H. M., Manzi, A. J., \& Glasscock, J. M. J. (2001). Relational influences in career development: A qualitative inquiry. The Counseling Psychologist, 29, 216-241. http://dx.doi.org/10.1177/0011000001292003

Strough, J., Patrick, J. H., Swenson, L. M., Cheng, S., \& Barnes, K. A. (2003). Collaborative everyday problem solving: Interpersonal relationships and problem dimensions. International Journal of Aging and Human Development, 56, 43-66. http://dx.doi.org/10.2190/Y3XN-RW1A-7EWT-KXTC 
Wegner, D. M., Erber, R., \& Raymond, P. (1991). Transactive memory in close relationships. Journal of Personality and Social Psychology, 61, 923-929. http://dx.doi.org/10.1037/0022-3514.61.6.923

Young, R. A., Marshall, S. K., Domene, J. F., Graham, M., Logan, C., Zaidman-Zait, A., ... Lee, C. M. (2008). Transition to adulthood as a parent-youth project: Governance transfer, career promotion, and relational processes. Journal of Counseling Psychology, 55, 297-307. http://dx.doi.org/10.1037/0022-0167.55.3.297

\section{Appendix}

Items of the Extended Perceptions of Collaboration Questionnaire (PCQ-E) and Confirmatory Factor Analysis $(\mathrm{N}=95)$

\begin{tabular}{|c|c|}
\hline & Factor Loadings \\
\hline Item & $\begin{array}{ll}\text { Unstan-da } & \text { Standar-di } \\
\text { rdized } & \text { zed }\end{array}$ \\
\hline
\end{tabular}

\section{Frequency}

F1. Very often we make decisions together.

F2. We frequently share tasks and make decisions together.

@1 .88***

$0.84 * * * .73 * * *$

F3. We always work together to deal with decisions.

$0.71 * * * \quad .63 * * *$

F4. It is rare for me to make decisions with him/her. (R)

\section{Cognitive Optimization}

CO1. When we combine our knowledge and experience, we make the best decisions.

@1 .76***

$\mathrm{CO}$ 2. Our knowledge fits together so well that it allows us to find the best solution.

$1.09 * * * \quad .76 * * *$

CO3. I am most confident in my decisions when we reach them together.

$1.05 * * * \quad .76 * * *$

CO4. Decisions are best thought through when we make them together.

$0.79 * * * \quad .56 * * *$

\section{Cognitive Compensation}

$\mathrm{CC} 1$. I need him/her to make up for knowledge or experience that I don't have.

$\mathrm{CC} 2$. I need to work together with him/her to feel confident in a decision or solution.

(a) 1 .48***

$1.64 * * \quad .79 * * *$

CC3. He/she usually thinks of important things that I overlook.

$0.70 * * \quad .46 * * *$

\section{Motivational Compensation}

$\mathrm{MC} 1$. I can remain highly motivated to follow through with a decision by myself. (R)

MC2. I am easily motivated to tackle problems without working together with him/her. (R) $0.93 * * * \quad .78^{* * *}$

MC3. Without him/her keeping me going I would put off making a decision.

$0.61 * * * \quad .44 * * *$

\section{Interpersonal Enjoyment}

E1. Solving problems and making decisions together brings us closer together.

(a) $115 * * *$

E2. Making decisions together makes me feel good about our relationship.

$1.07 * * * \quad .72 * * *$

E3. I enjoy working together with him/her.

$0.52 * * \quad .37 * *$

$* * * p<.001 . * * p<.01$.

Note. $(\mathrm{R})=$ reverse-scored item. Factorial structure of the PCQ-E was determined based on all participants' data (i.e., $N=95$ ) instead of only those of the 65 participants with major choice assessments. Compared to an alternative 1-factor model, $\chi^{2}=329.64, d f=119, C F I=.57, T L I=.51, R M S E A=.14, S R M R=.12$, the 5-factor model presented above, $\chi^{2}=159.31, d f=109, C F I=.90, T L I=.87, R M S E A=.07, S R M R=.08$, fit the PCQ-E data much better, $\Delta \chi^{2}(10)=170.33, p<.001$. 


\section{Copyrights}

Copyright for this article is retained by the author(s), with first publication rights granted to the journal.

This is an open-access article distributed under the terms and conditions of the Creative Commons Attribution license (http://creativecommons.org/licenses/by/3.0/). 